
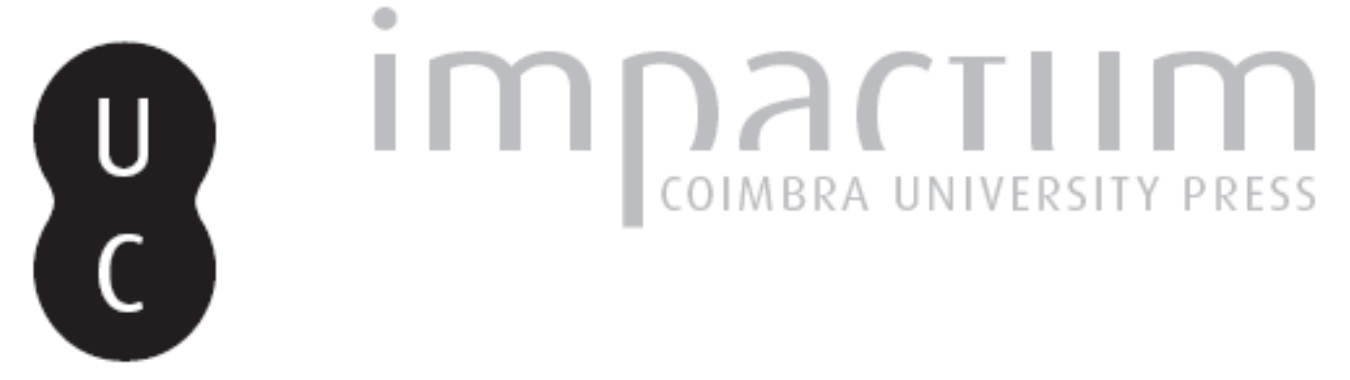

\title{
A evolução do conceito de risco à luz das Ciências Naturais e Sociais
}

Autor(es): $\quad$ Souza, Kátia Regina Góes; Lourenço, Luciano

Publicado por: Associação Portuguesa de Riscos, Prevenção e Segurança; Imprensa

URL

persistente: URI:http://hdl.handle.net/10316.2/38051

DOI: DOI:http://dx.doi.org/10.14195/1647-7723_22_1

Accessed : $\quad$ 26-Apr-2023 10:54:09

A navegação consulta e descarregamento dos títulos inseridos nas Bibliotecas Digitais UC Digitalis, UC Pombalina e UC Impactum, pressupõem a aceitação plena e sem reservas dos Termos e Condições de Uso destas Bibliotecas Digitais, disponíveis em https://digitalis.uc.pt/pt-pt/termos.

Conforme exposto nos referidos Termos e Condições de Uso, o descarregamento de títulos de acesso restrito requer uma licença válida de autorização devendo o utilizador aceder ao(s) documento(s) a partir de um endereço de IP da instituição detentora da supramencionada licença.

Ao utilizador é apenas permitido o descarregamento para uso pessoal, pelo que o emprego do(s) título(s) descarregado(s) para outro fim, designadamente comercial, carece de autorização do respetivo autor ou editor da obra.

Na medida em que todas as obras da UC Digitalis se encontram protegidas pelo Código do Direito de Autor e Direitos Conexos e demais legislação aplicável, toda a cópia, parcial ou total, deste documento, nos casos em que é legalmente admitida, deverá conter ou fazer-se acompanhar por este aviso. 


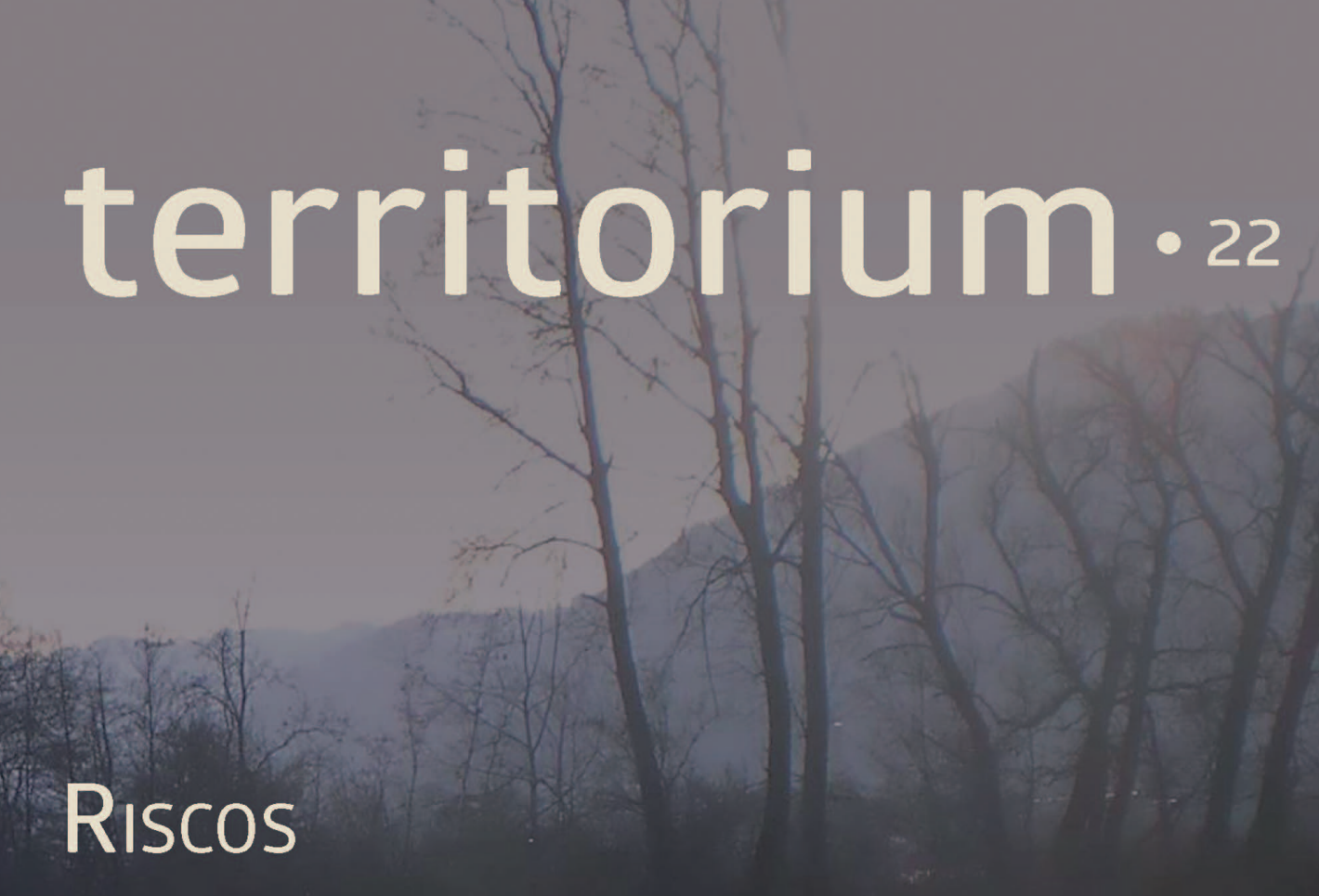

\section{TERRITÓRIOS DE CONVERGÊNCIA}

- Imprensa da Universidade de Coimbra Associação Portuguesa de:Riscos, Prevenção e Segurança 


\title{
A EVOLUÇÃO DO CONCEITO DE RISCO À LUZ DAS CIÊNCIAS NATURAIS E SOCIAIS*
}

\author{
THE EVOLUTION OF THE CONCEPT OF RISK IN THE LIGHT OF THE NATURAL AND SOCIAL SCIENCES
}

Kátia Regina Góes Souza

Universidade Estadual do Rio de Janeiro-UERJ, Rio de Janeiro, RJ, Brasil katia.goes@gmail.com

Luciano Lourenço

Departamento de Geografia e CEGOT Faculdade de Letras da Universidade de Coimbra luciano@uc.pt

\section{RESUMO}

O presente artigo visa desenvolver uma breve revisão acerca da evolução do conceito de risco, tendo como percursora a teoria global trazida à baila por Ulrich Beck e Anthony Giddens. 0 conceito de risco tem diferentes significados no âmbito das ciências sociais e naturais. Entretanto, envolto pela premente questão ambiental, o conceito vem sendo aperfeiçoado com o passar do tempo. Deste modo, entende-se ser importante resgatar sua trajetória sob diferentes abordagens científicas, visando compreender seus desdobramentos nos dias atuais e futuros.

Palavras-chave: Risco, vulnerabilidade, desastre, perigo.

\section{ABSTRACT}

This article aims to develop a short review about the evolution of the concept of risk, take as a precursor to global theory brought up by Ulrich Beck and Anthony Giddens. The concept of risk has different meanings in the social and natural sciences. However, involved by urgent environmental issue, the concept has been improved over time. Thus, it is understood to be important to rescue its trajectory under different scientific approaches, in order to understand its developments in current and future days.

Keywords: Risk, vulnerability, disaster, danger.

\section{RESUMEN}

La Evolución del Concepto de Riesgo a la Luz de las Ciencias Naturales y Sociales - Este artículo se centra en el desarrollo de un breve comentario sobre la evolución del concepto de riesgo, tomando como precursora la teoría global ejercida por Ulrich Beck y Anthony Giddens. El concepto de riesgo tiene diferentes significados en las ciencias sociales y naturales. Sin embargo, envuelto y con su enfoque en el tema ambiental, el concepto se ha burilado con el tiempo. Por lo tanto, se entiende que es importante rescatar su trayectoria bajo diferentes enfoques científicos, para entender sus desarrollos en días actuales y futuros.

Palabras clave: Riesgo, vulnerabilidad, desastres, peligro.

\section{RÉSUMÉ}

L'Evolucion de la Notion de Risque a la Lumière des Sciences Naturelles et Sociales - Cet article vise à développer un bref examen de l'évolution de la notion de risque ayant comme précurseur la théorie globale soulevée par Ulrich Beck et Anthony Giddens. La notion de risque a différentes significations dans les sciences sociales et naturelles. Cependant, entouré par la question pressante de l'environnement, le concept a eu plusieurs facettes au fil du temps. Ainsi, il est entendu d'être important pour sauver sa carrière sur sous différentes approches scientifiques, de comprendre ses développements dans les jours actuels et futurs.

Mots-clé: Risques, vulnérabilité, catastrophe, danger.

\footnotetext{
* O texto deste artigo foi submetido em 12-01-2015, sujeito a revisão por pares a 30-04-2015 e aceite para publicação em 07-07-2015. Este artigo é parte integrante da Revista Territorium, n. ${ }^{\circ} 22,2015,{ }^{\circ}$ RIscos, ISSN: 0872-8941.
} 


\section{Introdução}

Admite-se que os primeiros estudos técnicos sobre Risco e Incerteza surgiram na literatura em 1921, através do trabalho clássico intitulado como: "Risk, uncertainty and profit", de Frank Knight, que referiu "se você não sabe ao certo o que vai acontecer, mas as chances existem, isso é risco. Caso você não saiba quais são as chances, então é incerteza" (Adam, 1995, apud Castro, 2005). Ainda que já tivesse sido abordada nos anos de 1920, a concepção de risco do passado difere bastante das preocupações atuais. Com efeito, no passado a população era predominante rural e enfrentava numerosos processos perigosos tais como: frio, seca, inundações, furacões, o que dava à existência do homem uma atitude de constante precariedade e a exposição a calamidades era entendida como uma fatalidade. De acordo Lagrange (1993), o homem estava mais susceptível a catástrofes, fomes, epidemias que eram então percebidas como "signos da danação" ou seja como castigos divinos (Veyret, 2007).

Entretanto, as preocupações ambientais ganharam cada vez mais relevância e os problemas desencadeados, em sua maioria, recaem sobre o homem, deixando assim explicita uma mudança de paradigma na relação homem-natureza. Para Veyret (2007, p. 13), em nossa sociedade, o risco está em toda parte, prevalecendo um sentimento de insegurança que parece alimentado pelo desenvolvimento da ciência e de técnicas cada vez mais sofisticadas. Hoje, as sociedades modernas são mais vulneráveis e mais sensíveis do que no passado. As oscilações meteorológicas, que atualmente se traduzem em efeitos sobre a sociedade, são atribuídas à natureza, mas com uma responsabilidade que na verdade cabe também aos seres humanos. Não somente a natureza pode engendrar riscos, mas também a ciência e a técnica podem ser vistas como ameaçadoras e maléficas. Diante desse novo paradigma, o risco zero não existe, sendo preciso gerenciar o risco (Veyret, 2007, p. 15). Os efeitos da ciência moderna fogem do controle e os riscos passaram a ser globalizados para todos.

No meio acadêmico, intensifica-se a produção científica sobre o tema chegando-se a cogitar a inauguração de uma nova ciência chamada de Cindínica ou Cindinicologia (Faugères, 1991), cujo objetivo seria estudar e limitar os riscos aos quais estão expostas as populações (Dagnino, 2007). Desta forma, o uso indiscriminado das expressões, risco e perigo, causaram e ainda causam alguns equívocos que são perceptíveis em publicações de artigos que utilizam esses termos "concomitantemente ou intercambiado", mas que não deixam definidas as diferenciações existentes entre elas. 0 cerne da questão pode ser uma questão semântica, já que na língua portuguesa, risco e perigo, por vezes, podem surgir como sinônimos, ainda que não o sejam.
$\mathrm{Na}$ literatura, Hazard, é o termo técnico mais usado e por não ter uma palavra precisamente sinônima correspondente nas línguas latinas, acarreta conflitos conceituais (Marandola \& Hogan, 2003, Pedro, 2014). No panorama linguístico, as expressões mais utilizadas no meio acadêmico são: Risk, Hazard e Danger na língua inglesa e Risques e Danger, no Francês (Augusto Filho, 2001 apud Castro et al., 2005).

Diante da diversidade conceitual que abarca a questão dos desastres naturais, acredita-se que o melhor caminho a seguir será aquele que é ditado pelos padrões internacionais, fazendo os devidos ajustes, quando necessário, para a realidade local. Assim, para esclarecer os conflitos entre hazard, perigo e risco, recorreu-se a publicação UN-ISDR (2004), o que não resolve o problema, face à dificuldade em encontrar uma tradução para hazard. Por exemplo, para Marcelino (2008), o conceito de perigo é o que mais se aproxima do conceito de hazard, com a palavra hazard a significar alguma coisa que pode causar dano a algo ou alguém. Por sua vez, perigo representa uma circunstância que pronuncia um mal para alguém ou alguma coisa. Neste caso, existe semelhança entre perigo e hazard. No entanto, nem todos os autores concordam com esta tradução. Com efeito, Rebelo (1999, p. 5) conclui que hazard "pode perfeitamente traduzir-se por risco, em português", embora reconheça que nem sempre assim é, como demonstrou num dos seus últimos trabalhos (Rebelo, 2014).

De acordo com a UN-ISDR(2004) hazard é um evento de natureza física ou um fenômeno resultante da atividade humana, que pode causar um potencial prejuízo e perdas as estruturas sociais, econômicas e ambientais. Por sua vez, natural hazard pode ser definido como um processo ou um conjunto de fenômenos naturais que ocorrem na biosfera e que podem constituir um evento danoso. Deste modo, podem ser classificados em função da sua origem, a saber: geológica, hidro-meteorológica ou biológica. Estes eventos perigosos podem variar em magnitude ou intensidade, frequência, duração, área de alcance, velocidade de início, dispersão espacial e espaçamento temporal. Quanto a geological hazard, são processos naturais da Terra, tais como sismos e vulcões, que podem acarretar perdas sociais, econômicas e ambientais.

Tobin e Montz (1997) definem perigo como uma situação potencialmente prejudicial, enquanto que, desastre é a materialização do perigo. Para a UN-ISDR (2004) desastre é a interrupção instantânea de um sistema social que provoca perdas humanas, materiais, econômicas e ambientais. Neste caso, o desastre é uma função no processo de risco que traduz uma combinação entre processos perigosos, vulnerabilidade e incapacidade de conter os impactos negativos da manifestação do risco. Os fenômenos naturais fazem parte da dinâmica 
do sistema terrestre e só constituem risco quando esses eventos avançam sobre um sistema social, o que acarreta uma situação potencial de prejuízo a pessoas e bens (perigo). Caso o impacto produza danos e prejuízos extensivos e/ou de difícil superação pelas comunidades afetadas será então considerado como um desastre (Tobin e Montz, 1997).

O conceito de risco é sutil e isso pode causar certa inseguridade conceitual porque por vezes é difícil compreender o momento em que se passa do risco para o perigo e que se manifesta através do desastre. O conceito de risco pode ser interpelado como sendo anterior aos conceitos de perigo e desastre, e é mensurável por referir-se à probabilidade de ocorrência danosa para a sociedade. Segundo UN-ISDR(2004): risco "pode ser compreendido como sendo a probabilidade de consequências prejudiciais ou perdas esperadas (mortes, ferimentos, a propriedade, meios de subsistência, a atividade econômica interrompida ou ambiente danificado) resultantes de interações entre os riscos naturais ou induzidas pelo homem $e$ as condições vulneráveis. Convencionalmente risco é expresso pela notação de risco $=$ Processos potencialmente perigosos $x$ Vulnerabilidade. Embora exista uma tentativa mundial em uniformizar esses conceitos, alguns autores defendem que o desastre em si corresponde à situação de perigo que traduz a manifestação de risco. Algumas disciplinas incluem também o conceito de exposição para se referir em particular a os aspectos físicos da vulnerabilidade" (UN-ISDR(2004).

Para que haja uma situação de risco existem 2 condições preexistentes: a primeira delas uma população socialmente vulnerável. Esta pode se referir tanto a um setor de pobreza extrema como também setores residindo população mais abastados. A diferença entre a primeira e a segunda é a capacidade de resiliência diante de um evento severo. A segunda condição é a acomodação dessa população sobre ou em proximidades de áreas consideradas frágeis no aspecto físico, designadamente no climático. Outro fato é que estas populações podem estar em situação de risco mas podem nunca vir a ser expostas a situações de perigo, se os processos nunca se vierem a manifestar ou se o fizerem com baixa intensidade/severidade. Para Marcelino (2008), o risco é extremamente cambiante e apresenta uma dinâmica própria, que varia em função dos elementos naturais e sociais envolvidos no processo. Além disso, o risco não pode ser eliminado, mas pode ser gerenciado a tal ponto que se torne aceitável.

Para fazer a análise de risco é necessário estabelecer uma metodologia que determine a natureza e extensão do risco, analisando os processos potencialmente perigosos e as condições preexistentes de vulnerabilidade, que podem representar uma ameaça potencial e causar danos às pessoas, propriedades, meios de vida e ambiente de que dependem. 0 processo de avaliação dos riscos deve se basear em uma revisão das características inerentes aos processos envolvidos como sejam a sua localização no espaço (suscetibilidade) e no tempo (probabilidade), bem como a sua intensidade; além desta análise relativa à severidade (que alguns autores designam de perigosidade) deve ser tida em conta a vulnerabilidade, analisando os aspetos físicos, sociais, econômicos e as dimensões ambientais associados à exposição, sensibilidade/fragilidade e capacidade (de antecipação e de resposta), tendo especialmente em conta o enfrentamento de recursos pertinentes aos cenários de risco (UN-ISDR, 2004).

Para efetuar análises e avaliações de risco dispomos de excelentes instrumentos de análise geográfica e espacial, vulgarmente designados por Sistemas de Informações Geográficas (SIG). Estas ferramentas possibilitam a entrada de múltiplas variáveis (camadas) quer do meio físico (relevo, vegetação, drenagem, precipitação) e quer do meio social (população, ocupação do solo, pobreza, atividades econômicas, educação, etc.) de modo que estas fiquem superpostas facilitando a análise do fenômeno observado. Desta forma, para desenvolver análises de risco, com uso de geotecnologias, é necessário caracterizar a severidade (perigosidade) dos processos potencialmente perigosos, identificando a sua suscetibilidade, probabilidade e intensdidade, bem como a vulnerabilidade, através da exposição, sensibilidade e capacidade, podendo ainda estimar-se os danos potenciais, que se ilustram através do mapeamento das áreas de risco. A maior parte dos modelos destinados a avaliar riscos aplicam-se aos riscos naturais e, por isso, vários autores como Pearson et al., (1991); Smith (1992); Balaji et al., (2005) agrupam as camadas relativas ao meio geofísico (que caracterizam a severidade) e as referentes aos aspectos humanos, que associam à vulnerabilidade. Muitos autores ainda se encontram presos à fórmula inicial em que $\mathrm{R}=\mathrm{P} \times \mathrm{V}$, ou seja, o Risco (Probabilidade de dano) é igual à severidade da manifestação dos Processos (Geofísicos e Humanos) $X$ a Vulnerabilidade. Deste modo, as principais variáveis agregadas aos processos são a probabilidade de ocorrência (frequência) de escorregamentos, inundações, vendavais, terremotos, etc., bem como o local dessa ocorrência, traduzido na sua maior ou menor suscetibilidade ou propensão para registar fenómenos desse tipo e, por último, a sua intensidade/magnitude, expressa em graus, percentagem, $\mathrm{km} / \mathrm{h}, \mathrm{m} / \mathrm{s}$, etc. Em relação a vulnerabilidade ressaltam-se os elementos expostos tais como: infraestruturas urbanas, edificações, população, valores socioeconômicos e agropecuários, etc. Com efeito, de acordo com UN-ISDR(2004), a vulnerabilidade representa as condições determinadas por fatores ou processos físicos, sociais, econômicos e 
ambientais, que aumentam a susceptibilidade de uma comunidade ao impacto dos riscos. No entanto, apesar da cartografia ser um excelente instrumento da análise de risco, ela não resolve os problemas da terminologia (Lourenço, 2007).

Analisando a produção bibliográfica, dos autores mais relevantes, sobre risco, perigo, acidente, danos, ameaça, álea, vulnerabilidade e outros termos similares, observou-se que embora de forma um tanto confusa, esses conceitos foram evoluindo e se especializando em novas categorias que implicaram em agregar outros vieses científicos principalmente as novas escalas de análise, demonstrando que a teoria do risco tem estado cada vez mais latente na sociedade atual. Desta forma, este artigo procura apresentar uma breve evolução conceitual destes termos e também da relevância destes junto as ciências sociais e naturais, que apesar da similaridade entre os signos, foi ganhando novas nuances. Para melhor compreensão da dimensão alcançada por essas temáticas optou-se por iniciar o artigo abordando o paradigma que as envolve, ou seja, a teoria do risco; em seguida serão expostos os desdobramentos deste nas ciências naturais, principalmente na geografia e, por último, as consequências do risco em uma sociedade vulnerável. Neste contexto, este artigo divide-se basicamente em 4 partes: (i) as contribuições da geografia enquanto ciência natural e social, uma vez que ela se preocupou sobretudo com o estudo dos processos, o primeiro dos elementos na análise do risco; (ii) o conceito de vulnerabilidade à luz da demografia e sociologia, dado que a vulnerabilidade entra como segundo elemento na análise do risco; (iii) os conceitos de risco à luz da sociologia; (iv) as categorias da análise de risco.

\section{A contribuição da Geografia no arcabouço teórico conceitual do risco}

Com alguma frequência, na produção bibliográfica, o termo risco aparece associado ao meio natural e a fenômenos físicos presentes em estudos sobre potencial, fragilidade, susceptibilidade, vulnerabilidade, sensibilidade ou danos. De acordo com Marandola \& Hogan (2005), os estudos geográficos sobre risco, receberam tratamento especial de pesquisadores engendrados com fenômenos naturais que em situações extremas causavam danos e expunham as populações ao perigo. Esses estudos em geral, se destinaram a ações de planejamento e gestão e outras esferas que se preocupavam com a relação do homem com seu ambiente. De fato, os estudos quase sempre estiveram imbuídos com a compreensão do todo, no sentido de não se limitar a entender a extensão e o dano que os perigos causariam àquelas populações, mas principalmente visando o prognóstico da probabilidade daqueles fenômenos ocorrerem novamente. Com isso, alguns geógrafos, principalmente da área física, desenvolveram largamente o que se chamava avaliação de risco (risk assessment), ou seja, o estudo da probabilidade do risco vir a ocorrer em locais considerados susceptíveis à manifestação de processos perigosos.

Nesta perspectiva, risco é utilizado pelos geógrafos como uma situação futura que traz incerteza e a insegurança e que pode ser calculada através da probabilidade como mecanismo de funcionamento e previsão. Neste caso, poderia dizer-se que o risco se apresenta em áreas vulneráveis e susceptíveis, onde existe a probabilidade de, por acaso ou azar, ocorrer algum tipo de ameaça, perigo, problema, impacto ou desastre. Para Amaro (2005) a incerteza expõe "uma face premonitória" sobre a análise de risco dado que "embora as definições $e$ interpretações sejam numerosas e variadas, todos reconhecem no risco a incerteza ligada ao futuro, tempo em que o risco se revelará" . $\mathrm{E}$, em se tratando de probabilidade, Pelletier (2007), considera o risco como a probabilidade de que um evento, esperado ou não esperado, se torne efetivo. A ideia de que algo pode vir a acontecer, já configura um possível risco (Dagnino, 2007).

Smith (1992), na tentativa de esclarecer os conflitos entre os termos, define Risco como um fator probabilístico, independentemente de ser quantificável ou não e Hazard como evento potencialmente danoso que coloca algo em perigo. Para o autor a tradução de Hazard se aproxima de perigo. Dentro da mesma concepção, a autora Argentina, Aneas de Castro (apud Marandola, 2004), define risco como a probabilidade de realização de um perigo, enquanto desastre é o resultado de um perigo derivado do risco, com determinada magnitude. Observa-se que perigo é visto aqui tanto como fenômeno potencial, quanto como o fenômeno em si, o que significa dizer que "não há perigo sem risco e nem risco sem perigo” (Marandola, 2004, pag. 102).

No Brasil, os conflitos com esses termos técnicos não são diferentes. Risco era mais comumente utilizado pela Geologia e Engenharia, não sendo muito empregado o termo perigo, que para estes pesquisadores consideram como a "possibilidade de ocorrência de um acidente" (Cerri \& Amaral, 1998 apud Castro et al.,2005). Ainda dentro da visão da geologia, a expressão acidente, referese a um fato já ocorrido, com consequências desastrosas derivadas de ocorrências Geológicas (Zuquette \& Nakazawa (1998) apud Castro, 2005). Augusto Filho (2001), trabalhando na elaboração de cartas de risco de escorregamentos apresenta uma diferenciação para risco e perigo na qual considera Perigo (hazard) como a ameaça potencial à pessoa ou bens e risco (risk) como o perigo em termos de danos/por período de tempo, em geral, unidade monetária/ano (Zuquette \& Nakazawa, 1998 apud Castro, 2005). O mesmo autor traduz danger 
como processos perigosos (Castro et al. ,2005). Dentre os autores supra citados, observa-se que a definição entre risco e perigo não fica muito clara e também não diferente muito entre os demais autores. Contudo, pode-se dizer que estes tem comum a perspectiva para o meio natural.

Para Suzan Cutter, o termo hazard pode ser considerado uma ameaça a pessoas e as coisas que elas valorizam. Neste caso, "a ameaça surge da interação entre os sistemas social, natural e tecnológico e tem suas origens a partir de perigos ou azares naturais: terremotos, furações, escorregamentos, etc". No caso de risco (risk), a autora considera que o mesmo representa a probabilidade de ocorrência de um evento, de uma ameaça acontecer, ressaltando que as estimativas e quantificação da probabilidade de ocorrência está associada ao nível de segurança e também de aceitabilidade das análises de risco. Para concluir, categoriza que Risk is a component of Hazard e de forma semelhante, Kovach (1995), também usa a mesma abordagem de risco como componente do perigo estando sua estimativa envolvida em 3 aspectos: o risco de danos ao homem, o risco de danos a propriedade humanas e o nível de aceitação do risco (apud Castro et al., 2005).

Kenneth Hewitt (1997) traz para discussão a proposição de que um conjunto de elementos influencia as condições de risco (risk) e de segurança (safety). São eles: os perigos/ameaças (hazard), a vulnerabilidade e a intervenção e adaptação de perigo. Para o autor, hazard é frequentemente utilizado para descrever todo o campo de investigação, e são geralmente fenômenos e agentes físicos do ambiente natural e artificial que trazem consigo a ideia implícita de ameaça (Castro et al., 2005). Neste processo, vale destacar que embora haja preocupações com o meio natural, existe maior peso para as questões sociais e com os danos. Sendo assim, nos trabalhos de Hewitt (1997), Cutter (2001) e Cerri \& Amaral (1998), é possível perceber que a noção de perigo relaciona-se intrinsecamente com o processo/ evento a ocorrer, enquanto risco está sendo definido em função de uma escala ou hierarquia de probabilidade e de graus/níveis de aceitabilidade de ocorrência dos eventos perigosos. Neste caso, o processo perigoso é um componente do risco e a análise do risco compreende a identificação do perigos e pressupõe a quantificação e/ ou qualificação dos seus efeitos para a coletividade em termos materiais e imateriais.

Diferenciando um pouco dos demais e dissidente da visão integrada, Christofoletti (1990, p. 147) traduziu Natural Hazard como Azares Naturais e definiu como eventos que fazem interface entre os sistemas naturais e usuários dos sistemas socioeconômicos, mas que são considerados como azares na medida que ocasionam prejuízos e mortes a seres humanos. Nesta perspectiva, “Azares Naturais" é a tradução que melhor se adapta ao termo Natural Hazards. Deste modo, dentro da visão sistêmica, estão implícitos os conceitos de resistência e resiliência, que no primeiro caso, consiste na capacidade do sistema em permanecer sem ser afetado após distúrbios externos e, no segundo caso, na capacidade do sistema de retornar as condições originais após ser afetado por distúrbios externos (Christofoletti, 1990). Como os perigos caracterizam-se por eventos naturais que atingem diretamente os sistemas de usos humanos, as respostas têm de envolver aspectos da vida econômica e social, bem como dos sistemas naturais. Neste caso, a capacidade de absorção, reflete os ajustamentos necessários que a sociedade, as pessoas e o sistema ambiental são capazes de absorver em caso de perdas em possíveis impactos e de se recuperarem (Marandola \& Hogan, 2005).

A resposta ao perigo é a capacidade de diminuir perdas e de salvar vidas. Para isso chama-se a atenção para a importância da percepção do risco, como resposta fundamental que as populações darão ao perigo. As pessoas e os grupos sociais podem ter visão diferenciada do risco e, em geral, tal percepção está ligada aos princípios culturais de cada grupo (Marandola \& Hogan, 2005). Ainda sobre o assunto, pode-se dizer que grande parte dos estudos sobre risco e sua percepção estão associados a uma escala coletiva e isso se deve pela premissa desse tipo de estudo se concretizar para fins de políticas públicas, comunicação e cultura. Para Veyret e Meschinet de Richemond (2007, p. 49) a cultura do risco pode ser definida como uma percepção ou conhecimento da ameaça comum a um grupo social (apud Dagnino, 2007).

Torres (1998) considera que a utilização da categoria risco pressupõe um agente "ameaçador" e um agente "receptor" da ameaça e que a maior parte das ações humanas implica alguma forma de "cálculo" do risco implícito a um comportamento simples. Neste contexto, considera risco como a probabilidade de determinados indivíduos ou grupos serem ameaçados por fenômenos específicos.

Nas palavras de Yvette Veyret (2007), “O risco, objeto social, define-se como a percepção do perigo, da catástrofe possível. Ele existe social ou profissional, uma comunidade, uma sociedade que o apreende por meio de representações mentais e com ele convive por meio de práticas específicas. Não há risco sem uma população ou indivíduo que o perceba e que poderia sofrer seus efeitos. Correm-se riscos, que são assumidos, recusados, estimados, avaliados, calculados. O risco é a tradução de uma ameaça, de um perigo, para aquele que está sujeito a ele e o percebe como tal." (p. 12).

A autora vai além, citando que os campos de estudos de risco, acidentes e catástrofes não se limitam ao campo geográfico, mas que trata-se de uma abordagem global que integra os aportes provenientes das ciências naturais e físicas, ditas “duras” (geologia, geomorfologia, pedo- 
logia, etc.), bem como ciências sociais e humanas (sociologia, demografia, direito, economia, história, antropologia, ...). Com isso reitera a necessidade de uma abordagem que envolve várias outras ciências culminando a multidisciplinaridade que envolve os estudos sobre riscos, enquanto simbiose entre processos perigosos e vulnerabilidades.

\section{O conceito de vulnerabilidade à luz da demografia e sociologia}

Nesta segunda etapa, ocorrendo paralelamente à anterior, prepondera-se a introdução do conceito de vulnerabilidade, inserido mormente em um contexto urbano e com os respectivos desdobramentos sob uma perspectiva de análise com escalas mais detalhadas, ou seja, em pequenas áreas. Nesta fase, as questões de cunho social e econômico ganham maior relevância e voltam-se predominantemente para os sítios urbanos, fortalecendo o conceito de vulnerabilidade socioeconômica, que se insere em contexto demográfico através de estudos populacionais, agregados aos estudos de análise de risco.

Com a ampliação das perspectivas de estudo, a vulnerabilidade passa a ser vista como um atributo definido pelas condicionantes ambientais (biofísiconaturais) ou pelo recurso socioeconômico, que conferem maior capacidade de resposta diante dos perigos. Neste viés, outros autores ganham espaço ou agregam o conceito enriquecendo os estudos anteriores sobre risco e perigo.

Dentro desta abordagem, já se encontra mais consolidada a conscientização da complexidade e interdisciplinaridade que envolve o tema risco. Embora, o conceito de vulnerabilidade, já tivesse lugar nos primeiros estudos, nesta fase ganha maior foco no final da década de 80 e início da década de 90 (Marandola \& Hogan, 2005). O conceito de vulnerabilidade vai sendo burilado à luz da sociologia e demografia e nesse momento, fica mais evidente que perigos só existem a partir do momento em que há população atingida.

De fato, definir conceito de vulnerabilidade também não pode ser considerado uma tarefa trivial, como sucede como risco e perigo. Por se tratar de um tema que permeia várias ciências, o conceito de vulnerabilidade sofre com a fragmentação da abordagem que varia de acordo com a perspectiva dos pesquisadores que trabalham com essa temática. Ao consultar o dicionário da Língua Portuguesa para saber qual o significado da palavra vulnerabilidade verificou-se que esta referese a fraqueza, desprotegido, indefeso. Já na língua inglesa, vulnerability, tem outra conotação, fazendo alusão a susceptibilidade, a lesões física ou emocionais, susceptibilidade a ataque, criticidade, etc. Com relação a quem sofre a ação, Marandola \& Hogan (2005, p. 41) definiram que "grupos vulneráveis são aqueles que apresentam características específicas que os tornam susceptíveis aos riscos e a delimitação desses grupos encontram-se engendrados a componentes tanto da dinâmica social quanto da dinâmica demográfica".

No arcabouço teórico-metodológico, em geral, os estudos que envolvem vulnerabilidade estão ligados a dois pontos de vista distintos: a visão de quem é afetado (demografia) e a região ou ambiente vulnerável (geografia). Embora a produção bibliográfica sobre o tema seja vasta, procurouse focar autores mais relevantes que ajudassem a esmiuçar o conceito almejado por esta pesquisa.

Inicialmente o conceito de vulnerabilidade foi utilizado pela engenharia referindo-se ao nível resistência de materiais, frente a ações de ameaças naturais (ventos, terremotos, água). Somente a partir dos anos 80 é que este termo passou a ser relativizado com impactos de desastres naturais e antrópicos. Já os autores Klein \& Nicholls (1999, apud Nascimento, 2011), em um trabalho sobre a elevação do nível do mar, especificaram o sentido do termo vulnerabilidade, desdobrando-o em vulnerabilidade socioeconômica e vulnerabilidade natural. Porém, explicitaram que para trabalhar com a vulnerabilidade social é necessário conhecer a vulnerabilidade natural que compreende o estudo de 3 propriedades:

- Suscetibilidade - potencial de ser afetado;

- Resistência - capacidade de resistir ao impacto;

- Resiliência - celeridade de recuperação após impacto. Já para o Programa das Nações Unidas para o MeioAmbiente (PNUMA), vulnerabilidade é a condição determinada por fatores ou processos físicos, sociais, econômicos e ambientais que aumentam a susceptibilidade aos impactos de desastres (Nascimento, 2011). Para Smith (1992), os estudos sobre vulnerabilidades não podem se limitar ao reconhecimento das dinâmicas naturais dos perigos em evidencia, muito menos apenas ao estudo dos recursos sociais para lidar com o perigo. Para o autor é fundamental compreender a relação existente entre esses condicionantes, para evitar os dois enganos: supervalorizar os fatores ambientais ou dinâmica social. Opostamente, Brookfield (apud Marandola \& Hogan, 2005), propõe que os estudos sobre vulnerabilidade sejam focados na resistência e sensibilidade do ambiente e não partindo do uso social da vulnerabilidade, pois uma abordagem assim, em sua opinião, pode acabar mascarando as causas naturais envolvidas no processo. 0 autor preocupa-se mais com as causas biofísicas do perigo (Marandola \& Hogan, 2005).

Dilley e Bourdreau (2001) empregaram o termo vulnerabilidade na área de nutrição. Neste trabalho, vale destacar a necessidade de identificar em relação ao 
dano: quem sofre, porque sofre e em que nível os grupos são vulneráveis. Watts e Bohle (1993, apud Kalipeni, 2001), propõem uma estrutura tripartida para construir o conceito de vulnerabilidade, que consiste em conjugar o direito das pessoas (entitleman) a participação política coletiva (empowerment) e a política econômica (Nascimento, 2011).

Dentre outras perspectivas, vale ressaltar também a perspectiva da sociologia urbana que é fortemente influenciada pela Escola de Chicago. Para estes pesquisadores a importância da localização e da posição relativa é trazida para o estudo social, na medida em que foram sendo acrescentadas as preocupações ecológicas, quando a base para seus estudos são situações de pobreza e privação (Nascimento, 2011).

Por sua vez, Wisner (1998) definiu que vulnerável é aquele indivíduo ou população que se expõe aos perigos/ameaças. Para o autor, o risco é um processo e vulnerabilidade, mas também é a capacidade de luta e de recuperação que o indivíduo pode apresentar. Entretanto, o nível socioeconômico, a forma de ocupação e a nacionalidade também podem ajudar na composição do processo de vulnerabilidade, já que o nível socioeconômico, a forma de ocupação e a nacionalidade podem ter repercussão sobre importantes aspectos concernentes ao acesso a informação, aos serviços e a disponibilidade de recursos para a recuperação que reverberar produzindo maior ou menor vulnerabilidade (Nascimento, 2011).

Marandola \& Hogan (2009), em uma tradição alicerçada pela sociologia, que direciona os estudos sobre pobreza, citam que embora a sociologia e a geografia sejam distintas, para análise da vulnerabilidade se imbricam pela relevância espacial contida nesses estudos. Para eles, o resultado são duas abordagens que ora se distanciam e ora se tocam priorizando um e outro ângulo: vulnerabilidade ambiental ou do lugar e a vulnerabilidade social ou sóciodemográfica.

Para a vulnerabilidade ambiental ou do lugar, os estudos populacionais se voltam para grupos demográficos que estão sujeitos a perigos, ou seja, população em situação de risco. A necessidade de analisar a população e seu entorno (ambiente) proporcionou a dimensão espacial a problemática. Com isso, acrescentam-se os estudos os elementos que oferecem perigos e outros que possibilitam seu enfretamento. Nesse viés, sob a perspectiva demográfica, muitos trabalhos tem contribuído para compreensão dessa abordagem e que consideram os fatores biofísicos dos ambientes e sua inter-relação com a dinâmica demográfica (Marandola \& Hogan, 2005).

Nessa abordagem, Torres (1998) procura elaborar um plano lógico para enfrentamento do risco, percepção do risco e população envolvida, para o que aponta 4 dificuldades e 5 passos.
No conjunto de dificuldades destacam-se:

- Os riscos que apenas serão conhecidos quando seus efeitos negativos já tiverem afetado muitas pessoas e, às vezes, em processos irreversíveis.

- A noção de que o que é arriscado é definido historicamente, podendo transformar-se ao longo do tempo;

- A percepção dos indivíduos e das famílias acerca do risco pode ser bastante diferente, por diversos fatores, mesmo que o risco seja relativamente conhecido;

- A capacidade dos indivíduos ou grupos sociais de se proteger é afetada pelo nível de renda.

No conjunto de passos lógicos destacam-se:

- Identificação de uma fonte/fator potencialmente geradora de riscos ambientais;

- Construção de uma curva de riscos (real ou imaginária);

- Definição de um parâmetro de aceitabilidade do risco;

- Identificação da população sujeita a risco;

- Identificação do grau de vulnerabilidade.

Nesta proposição, Torres (1998) visa observar as características socioeconômicas das populações em situação de risco, em que a demografia tem de pensar em uma escala de análise intra-urbana, que utiliza setores censitários ou pequenas áreas e fatores com a distribuição de renda, escolaridade, raça, tipo de ocupação, entre outros, os quais devem receber atenção juntamente com as variáveis demográficas clássicas. 0 que se pode afirmar que nesta perspectiva é que a questão da vulnerabilidade aparece vinculada à situação socioeconômica e à capacidade de resposta (ou de enfrentamento) diante dos riscos ambientais. Fazendo um paralelo com a análise da geografia, em suas indagações o autor expõe uma nítida referência sobre as suas preocupações relativas à necessidade de criar recortes espaciais, escala de análise e de distribuição dos fenômenos.

A vulnerabilidade social ou sóciodemográfica tem uma abordagem qualitativa que trabalha contiguamente com a Geografia Humanista e Cultural, colocando o fenômeno como foco essencial, encarando a experiência espacial como principal mediação entre o indivíduo e o ambiente (Tuan, 1983). Deste modo, espera-se que a identificação do ambiente corresponda a uma infinidade de significados onde a pessoa está inserida (Nascimento, 2011).

Com ampla repercussão internacional, a linha da vulnerabilidade sóciodemográfica, tem como pano de fundo o cenário latino-americano. Os estudiosos desta vertente 
estão associados ao Centro de Latino Americano y Caribeño de Demografia (Celade) e à divisão da Comisión Económica para America Latina y El Caribe (Cepal). Grande parte desses estudos está centrada na discussão das desigualdades sóciodemográficas, vinculadas à pobreza e à exclusão social, considerando "grupos vulneráveis aqueles que apresentam características específicas que os tornam susceptíveis aos riscos". Devido a essa preocupação com a pobreza, surgiu a expressão ativos, que refere-se a uma estrutura profunda de recursos (capitais humanos, sociais e físicos) distribuídos desigualmente numa sociedade em diversos lugares. Neste viés, a vulnerabilidade é compreendida como a menor capacidade de disponibilidade, acesso ou capacidade de manejar esses ativos organizados dentro de uma estrutura de oportunidades (Marandola \& Hogan, 2005).

De acordo com Cutter (apud Marandola \& Hogan, 2005), essa abundância de abordagens decorre da própria riqueza na diversidade de temas e espaços estudados, bem como da própria orientação epistemológica e suas consequências práticas metodológicas. Essas diferenças resultaram em 3 posturas principais:

- Uma se detém a focar a probabilidade de exposição (biofísica ou tecnológica);

- Outra se preocupa com a probabilidade de consequências adversas (vulnerabilidade social);

- E a última combina as duas anteriores.

Susan Cutter enfatiza a necessidade de se trabalhar a vulnerabilidade de forma transdisciplinar, associada a uma metodologia. Contudo, destaca que os estudos de vulnerabilidade ajudam a compreender as circunstancias em que as pessoas estão expostas ao risco. Para a autora, a ciência da vulnerabilidade (Vulnerability Science) provê a base para o estudo dos riscos, perigos e políticas para redução de desastres. Em suas análises, chama a atenção para as seguintes tendências da vulnerabilidade (Cutter, 2003, p. 6 e 8):

- Vulnerabilidade como condição preexistente, que em geral foca a distribuição e ocupação de áreas perigosas e o grau de perda associado ao evento;

- Vulnerabilidade como resposta controlada, que se preocupa com a capacidade de absorção sobre a resposta da sociedade e com a resposta da sociedade, incluindo a resistência e a resiliência social para com os perigos;

- Vulnerabilidade como perigo do lugar na qual se incorpora a mensuração do risco biofísico, a produção social do risco e as capacidades de respostas, tanto da sociedade (grupos sociais) quanto dos indivíduos (Marandola \& Hogan, 2005, p. 34).

Marandola (2004) adota uma perspectiva mais ampla da vulnerabilidade e de risco, na qual pretende conciliar riscos/vulnerabilidade em um sentido multidimensional que nos permita trabalhar com os dois enfoques (geográfico e demográfico) de forma confluente aos enfoques ambientais e sociais. A diferença na proposta do autor é o surgimento da experiência relacionada com a percepção do risco que está associada à construção sociocultural. Com isso tende para uma visão antropocêntrica, ou seja, foca-se no risco/ vulnerabilidade das pessoas/famílias, entendendo, porém, que para esta delimitação os fatores de diferentes dimensões são fundamentais, entre eles, o lugar, ou seja, o espaço (e todas as suas implicações) onde aquela pessoa/família vive (Marandola \& Hogan, 2003).

Ainda na área da demografia, a vulnerabilidade também pode ser conceituada como um conjunto de características sócio-demográficas de domicílios ou indivíduos que limitam a acumulação de recursos. Esta perspectiva revela características desfavoráveis e relacionadas com outras manifestações de desvantagens sociais que podem ser delineadas por levantamentos censitários. Para Vinoli (2000), as desvantagens sociais (baixa renda e vidas precárias, necessidades básicas insatisfeitas) afetam negativamente o desempenho das comunidades, pessoas e lugares (Nascimento, 2011).

Uma outra contribuição, dada por Cutter (2003), procura estabelecer também uma reciprocidade entre o contexto social e o espacial. Entretanto, destaca-se aqui o enfoque metodológico na análise por áreas (risco/vulnerabilidade de lugares/áreas) e na análise por pessoas (risco/ vulnerabilidade de pessoas/famílias). Os geógrafos já há algum tempo vêm trabalhando com abordagens culturais e humanistas, que enfocam relações de pertencimento, envolvimento e metodologias de certa forma próximas da antropologia. Por outro lado, os demógrafos, em especial aqueles que estão envolvidos com a problemática ambiental, têm-se valido muito da análise por áreas, trabalhando inclusive com análise espacial, geoestatística e Sistemas de Informações Geográficas (SIG). Com isso, observa-se que as disciplinas não são excludentes, pois, na verdade tratase de uma forma de diálogo entre elas, visto que conjugando as abordagens se amplia a capacidade de análise, aumentando as dimensões da vulnerabilidade (Marandola \& Hogan, 2005).

Nas palavras de Suzan Cutter (2003), as visões geográficas e demográficas podem se complementar através de modelagens, construção de indicadores biofísicos e sociais e utilização de Sistemas de Informações Geográficas como ferramenta. Para a autora, o uso de sistemas espaciais como os SIG, proporciona a dinâmica necessária aos estudos de vulnerabilidade, por eles integrarem fontes diversificadas de dados e associada a modelos que auxiliam enormemente a visualização do risco e da vulnerabilidade. 


\section{0 conceito de risco à luz sociologia}

Em geral a forma como o homem se relaciona com a natureza revela uma ideologia atuante, cujo paradigma é um referencial teórico-filosófico que se desdobra diretamente sobre todas as esferas das relações sociais, econômicas e ambientais. É neste contexto de intensos processos de desequilíbrios do meio ambiente, provocados pelo mau uso dos recursos naturais, que a sociologia traz à baila a teoria da sociedade de risco, representados pelos sociólogos Ulrich Beck (alemão) e Anthony Giddens (Inglês) em meados dos anos de 1980.

A teoria da sociedade de risco se consolida em 1986 através do sociólogo alemão Ulrick Beck, com sua obra: Sociedade de risco: rumo a uma nova modernidade (Risikogesellschaft: Aufdem Weg in eine andere Modern), na qual o autor propõe uma divisão entre a primeira modernidade, representada pela industrialização, sociedade estatal e nacional, e a segunda modernidade, que é reflexiva, marcada pelas insuficiências e antonímias da primeira. Para este autor, vivemos em uma sociedade de risco porque a sociedade industrial não foi pensada para tratar os riscos associados à produção industrial e os males provocados pela atividade fabril são distribuídos de forma igualitária (Guivant, 2001).

No meio científico, Beck foi visto como um autor pessimista, já que aponta o progresso da sociedade industrial como sinônimo de destruição em nível global, justificando como marco para o surgimento da sociedade de risco, o acidente da usina nuclear de Chernobyl, até então considerada como uma das usinas mais seguras do mundo. A partir deste fato, a sociedade começou a questionar a definição de segurança e se o progresso tecnológico seria de fato bom para manter o bem estar social. Para Beck (op. cit., p. 14), os riscos antes eram pessoais ou locais, mas agora passaram a ser globais, atravessando fronteiras nacionais e classes sociais. Em suas palavras: "O poder aquisitivo não é mais sinônimo de segurança. Deste modo, o risco é democrático e atinge a todas as camadas sociais". Outro fato importante que deve ser abordado, refere-se à transformação da sociedade em grande laboratório a céu aberto, onde os efeitos colaterais admitidos pela ciência assumem falta de conhecimento a respeito do produto que está sendo lançado no mercado, mas que este fato não impede sua comercialização, onde efeitos colaterais mencionados anteriormente passam a ser considerados uma margem de erro, ou seja, risco calculado (Guivant, 2001).

Mais recentemente, Anthony Giddens (1991, apud Pessanha, 1998, escreveu: “Em condições de modernidade o industrialismo se tornao eixoprincipal dainteração dosseres humanos com a natureza. A Indústria moderna modelada pela aliança da ciência com a tecnologia transforma o mundo da natureza de maneiras inimagináveis" (p. 7).
Para o autor, a modernidade é um processo de destradicionalização, em que esta dinâmica comporta vários mecanismos de desencaixe, dentre os quais podem ser citados:

- Fichas simbólicas - que circulam sem demonstrar quem forneça uma característica pessoal de sua origem;

- Sistemas peritos - que se caracterizam pela excelência técnica organizada nos diversos ramos da ciência: engenharia, medicina, arquitetura, nos quais é depositada confiança sem nenhum questionamento dos resultados;

- Reflexividade - que está ligada intimamente ao ritmo da modernidade, uma vez que está vinculada à rotina e à dinamização da vida cotidiana, onde pensamento e ação se combinam. O conhecimento é revisado e alterado a todo instante pela própria prática, conotando volatilidade e multiplicidade de informações (Pessanha,1998).

Sobre a questão do risco, Giddens (apud Pessanha, 1998) considera que o mundo globalizado pós-moderno é um mundo perigoso e que a era moderna caminha e desenvolve-se sob a luz do risco, estabelecendo uma relação de confiança entre seres humanos e sistemas peritos, com o objetivo de minimizar ou neutralizar o risco. Contudo, tanto Beck quanto Giddens compartilham da ideia de que o ônus trazido pela industrialização do planeta e da exploração depredatória do homem sobre a natureza trouxe riscos de sobrevivência no nível planetário. Assim, como resultado da reflexividade moderna, a certeza foi substituída pela dúvida, fato que foi acarretado pela disseminação do conhecimento, onde indivíduos comuns (leigos) se apropriaram do conhecimento perito. "O risco ocorre justamente no momento em que o consumidor navega num mar de informações que surgem dos meios de comunicação, da ciência, do conhecimento local, para assim tomar sua decisão" (Pessanha,1998, p. 12).

O fato é que o mundo pós-moderno é uma incógnita onde não há certezas absolutas a respeito do futuro. 0 que se observa, paradoxalmente, é que os malefícios trazidos pela revolução industrial tecnológica são compartilhados igualitariamente sobre a superfície planetária, desconsiderando qualquer sistema de fronteira, enquanto o conhecimento, tal qual ocorria na idade média, está sob o controle de um grupo dominante. Segundo Bauman, "a sociedade de risco pede segurança, os riscos são um lucrativo negócio no mercado global" (apud Pessanha, 1998). Para Yvette Veyret (2007, p. 16), na análise do alemão Beck (1986), o risco é o conceito central do século $\mathrm{XX}$, que inicialmente se insere em uma visão catastrófica e negativa, mas que, posteriormente, pode tornar-se num aliado para o crescimento econômico. Segundo a autora, este conceito passa por 3 momentos distintos: 
- Em um primeiro momento, em meados do século XX, esse conceito se expande e se associa à ideia de crise, relacionado a aspectos ecológicos e econômicos, tornando-se fruto de concepções da comunidade científica como os ecologistas que denunciam o impacto das sociedades sobre a natureza, lamentam o intenso crescimento demográfico e se inquietam com a industrialização e urbanização;

- Em um segundo momento, os técnicos e a mídia se apossam do conceito de risco, mais especificamente focando assuntos relacionados à segurança ambiental e ao perigo das instalações industriais;

- Em um terceiro momento, ocorre um recuo do campo técnico, dando lugar a preocupações com a gestão do risco.

Por fim, a autora conclui que o "risco onipresente na sociedade mundial pode torna-se um fator de crescimento econômico tanto no que se refere a pesquisas científicas e técnicas, quanto para o desenvolvimento de certos setores econômicos" (Veyret, 2007).

No tocante à teoria da sociedade de risco, pode-se dizer que o ponto central da discussão é a confiança e os sistemas peritos, e a sociologia, através das contribuições que os autores Beck e Giddens trouxeram para o debate, preocupações que antes não tinham tanta relevância no meio científico, dentre estas a questão da percepção e da aceitabilidade do risco, bem como do nível de risco calculado, nas quais devem ser creditadas a confiança (Castro et al., 2005). Todos esses elementos envolvem uma visão de confiança que Antony Giddens entende ser diferente de crença. Para o autor, ao seguir um curso especifico de ação, a confiança está ligada ao reconhecimento consciente das alternativas através do cálculo dos riscos. Já para a crença, essas alternativas não são consideradas e muito menos a possibilidade de assumir possíveis riscos. Com isso, o autor defende a necessidade de se redefinir o termo confiança como a crença na credibilidade de uma pessoa ou sistema, tendo em vista um conjunto de resultados ou eventos (apud Castro et al., 2005). Observa-se aqui uma inquietação social e uma necessidade urgente de criar mecanismos de segurança que vão do léxico dos termos técnicos a ações efetivas.

Outro ponto que vale destacar se refere à mudança na relação de confiança com a ciência, que em uma atmosfera de incerteza e insegurança, passa a ser vista como "vilã". Para Giddens, a confiança nos sistemas peritos é uma característica da modernidade, visando reduzir ou mesmo minimizar os riscos típicos de várias atividades, mas em que o próprio funcionamento e a existência destes sistemas, muitas vezes, depende da confiança dos leigos. Sendo assim, tantos os peritos quanto os sistemas peritos podem ser falhos. Na esfera ambiental, é necessário compreender os processos que determinam diferentes usos do ambiente "natural" e a construção do ambiente propriamente dito pela sociedade, na sua dimensão social e produtiva (apud Castro et al., 2005).

\section{Categorias de Análise de Risco}

Conforme foram ocorrendo os avanços e os investimentos nos estudos sobre riscos pode-se observar 3 abordagens principais: a primeira relacionada com as geociências, com enfoque a processos catastróficos e rápidos, ligada aos riscos naturais; a segunda refere-se a estudos de riscos tecnológicos e sociais, associada aos riscos antrópicos que, como os anteriores, envolvem a atuação da defesa/proteção civil; a terceira abordagem, ainda que associada a uma origem antrópica, não implica a intervenção da defesa/proteção civil, e trata de riscos com características e consequências bem distintas, designadamente em termos empresarial e financeiro.

Assim, como atualmente os estudos acerca dos riscos vêm sendo desenvolvidos em vários setores, via de regra são acompanhados por um adjetivo que os qualifica: risco ambiental, risco social, risco tecnológico, risco natural, risco biológico e tantos outros associados a segurança pessoal, saúde, condições de habitação, trabalho, transporte, ou seja, do cotidiano da sociedade moderna (Castro et al.,2005)

Quanto às categorias de análise de risco, existem diversas classificações, sendo uma das mais conhecidas no Brasil a de Egler (1996), que destaca quatro categorias como as mais relevantes por serem mais citada na literatura. São elas: risco natural, risco social, risco tecnológico e risco ambiental, que representa a união de todas essas categorias.

Risco Natural ou Telúrico: o "risco natural é usualmente associado ao comportamento dos sistemas naturais, considerado o grau de estabilidade e de instabilidade expresso pela vulnerabilidade natural a eventos de curta ou longa duração" (Castro et al., 2005). Segundo Egler (1996), a análise deste tipo de risco está relacionada às atividades que interferem direta e indiretamente com os processos da dinâmica superficial ou interna da Terra (processos endógenos e exógenos), a forma como os recursos naturais estão sendo utilizados e também com o crescimento demográfico de sítios urbanos. Existem ainda outras subdivisões de risco natural: riscos tectônicos e magmáticos, climáticos, hidrológicos e geomorfológicos, estando os mais típicos destes representados por ravinamentos, movimento em massa, quer sejam desabamentos quer se trate de deslizamentos, e, ainda, erosões hídricas e eólicas. A expressão risco telúrico foi utilizada por Sevá Filho (1988, apud Dagnino, 2007). 
Risco Tecnológico: "Este tipo de risco é frequente $e$ se circunscreve ao âmbito dos processos produtivos $e$ à atividade industrial". Em geral, surge a partir de falhas internas decorrentes da tecnologia industrial e que ao contrário dos processos naturais, são percebidas como ameaça externa (Castro et al., 2005). Segundo Filho (1988), a análise deste tipo de risco deve ter em consideração 3 fatores indissociáveis: o processo de produção (recursos tecnológicos), o processo de trabalho (recursos humanos) e a condição humana (individual e coletiva). Onde houver um desses fatores pode se caracterizar um risco tecnológico (Dagnino, 2007).

Nas palavras de Egler (1996): "Esta categoria de risco pode ser definida como o potencial de ocorrência de eventos danosos à vida, no curto, médio e longo prazo, em consequências das decisões de investimentos na estrutura produtiva. Para avaliar este tipo de risco devese fundamentar na densidade da estrutura produtiva $e$ no seu potencial de expansão e na gestão institucional e ambiental das empresas" (p. 34).

Risco Social: A grande maioria dos riscos são sociais, e estes implicam pluralidade de atores e resultam da combinação de grande número de variáveis que são difíceis de combinar simultaneamente. Neste caso, Vieillard-Baron (2007), distingue 2 tipos de riscos sociais que podem afetar a sociedade humana. São eles: riscos exógenos, relacionados aos elementos naturais e às ameaças externas, como terremotos, epidemias, secas e inundação, e os risco endógenos, que se relacionam diretamente a produtos da sociedade e às formas de política e de administração adotadas, ao crescimento urbano e à industrialização, ao povoamento e densidade excessiva.

Para (Castro et al., 2005) existem pelo menos 3 possibilidades de análise desta categoria:

- Pode ser considerada como o dano que em uma sociedade (ou parte dela) pode ser causado, como em casos de conflitos militares armados;

- Pode também referir-se a marginalidade e vulnerabilidade causada por desastres naturais;

- Na visão mais abrangente, como apresentado por Egler (1996), pode ser analisado como resultante das carências sociais que contribuem para a degradação das condições de vida da sociedade.

Risco Ambiental: Para esta categoria de risco, é necessário se valer da análise integrada, para ter uma visão da totalidade do problema e compreender como suas esferas se superpõem e interceptam, já que esta tipologia de análise se preocupa em entender as situações de risco através da avaliação do seu entorno, ou seja, da dinâmica sistêmica em seu sentido amplo. Neste viés, risco ambiental pode ser considerado um termo sintético que abriga as demais categorias de risco natural, tecnológico e social.

De acordo com Egler (1996, p. 20): "Para compor o quadro de risco ambiental, deve-se agregar na proposta de estudo, desde a ocorrência de perigos naturais (catástrofes) e impactos da alocação de fixos econômicos no território, até as condições de vida da sociedade, o que implica em avaliação em diferentes escalas $e$ períodos de tempo. Para tanto, o autor utiliza-se das categorias de risco natural, risco tecnológico e risco social. Tais categoriais tendem cada vez mais a ser menos utilizadas devido a complexidade existente entre si".

Para Veyret e Mesquinet (Veyret, 2007), risco ambiental resulta da associação entre os riscos naturais e os riscos decorrentes de processos naturais agravados pela atividade e pela atividade humana e ocupação do território.

De certo, na tradição demográfica a noção de risco difere da tradição da geografia, uma vez que para os demógrafos, o risco está associado às probabilidades de ocorrerem certos eventos na dinâmica demográfica. Esse risco é fruto de um cálculo matemático, que tem seus elementos definidos de acordo com a natureza de tal fenômeno. Calcula-se principalmente o risco de morte ou o risco de contrair uma determinada doença. O risco é uma fração matemática expressa por um índice que varia de 0,0 (impossibilidade de ocorrência) a 1,0 (absoluta certeza de ocorrência). 0 risco nesse entendimento, é um elemento probabilístico estritamente neutro, não carregando uma carga negativa em si, como ocorre nos estudos dos geógrafos e como é encarado o risco, em geral, desde a entrada da modernidade. Assim, mais importante na tradição demográfica é a delimitação e o conhecimento dos fatores de risco (Marandola \& Hogan, 2005, p. 37)

Finalizando esta parte, ressalta-se que, inicialmente, na visão geográfica, os estudos voltavam-se para escalas mais abrangentes, abarcando eventos de grandes magnitudes resultantes de processos endógenos e exógenos como: vulcanismos, terremotos, deslizamentos, enchentes e principalmente evento climáticos. Neste caso, especificamente, o risco era visto como hazard, ou seja, uma categoria de análise na qual considera a probabilidade de ocorrência de um processo natural capaz de produzir um desastre. Deste modo, não existe risco sem possíveis danos, a coisas e pessoas, como, a percepção do risco está diretamente ligada ao coletivo do grupo social envolvido.

Neste contexto, quanto à sua génese, os riscos podem ser agrupados em naturais e antrópicos (Rebelo, 2001) ou, como alguns deles podem ter ambas origens, há autores que os consideram naturais, antrópicos e mistos (Lourenço, 2007 e 2013). 


\section{Conclusão}

No atual contexto de preocupações com o futuro do planeta, decorrentes das previsões de aquecimento global e, paralelamente, da ocorrência de sucessivos eventos naturais adversos, de cunho meteorológico e geofísico, que transcendem entre as escalas local e global, tais como furações, ciclones, tromba d'água, tsunamis, atividades vulcânicas e tremores de terra, as discussões sobre a temática dos processos perigosos e das vulnerabilidades que determinam o risco tendem a ganhar cada vez mais relevância. Com isso, o arcabouço teórico-conceitual sobre a teoria do risco vai sendo burilado e ajustado a novas situações (escala local) ou a novos paradigmas (escala global). Embora o conceito se atualize, o que não se pode perder de vista é o que está no cerne dessas discussões, ou seja, o que está in voga, que é sempre a relação ser humanonatureza, ou seja, o homem, o ambiente e a sociedade.

Sendo assim, cabe ressaltar que existem muitos estudos e trabalhos de pesquisas de excelente qualidade sobre situações de risco, sociedades vulneráveis e localidades frágeis, e que estes, infelizmente, não são utilizados preventivamente pelos gestores públicos para tomada das suas decisões, mas apenas são usados no pós-acidente como constatação da eficiência do estudo. 0 que se nota, em diversas circunstâncias, é que existem problemas em relação a planejamento e gestão do território, assim como de intercâmbio entre essas duas esferas da sociedade, contribuindo negativamente para uma sociedade que fica mais vulnerável por falta de conhecimento dos ambientes frágeis e das áreas de risco de seu território.

Quanto às diferentes contribuições provenientes das ciências sociais e naturais, não há dúvida de que as diferentes visões da ciência têm contribuindo para ampliar os espectros de análises de risco e vulnerabilidade. Contudo, de forma simplória, observa-se que nas três ciências referidas no presente estudo: Sociologia, Geografia e Demografia, houve uma aproximação nas abordagens e no tratamento a diferentes escalas: mundial, regional e local.

Por último deve-se esclarecer que devida a extensão de publicações sobre a temática de risco, foi inevitável a redução no aporte teórico, dando maior ênfase aos autores que mais se aproximam dos estudos que envolvem a realidade no Brasil, ou seja, riscos de deslizamentos e de enchentes. Todavia, a bibliografia é rica e toda a produção converge para esclarecer e prevenir o risco.

\section{Referências Bibliográficas:}

Amaro, António (2005). Consciência e cultura do risco nas organizações. Revista Territorium, n.12, Coimbra, p.5-9. Disponível em: http://www. uc.pt/fluc/nicif/riscos/Documentacao/ Territorium/T12_artg/T12art02.pdf.
Augusto Filho, Osvaldo (2001). Carta de risco de escorregamento quantificada em ambiente SIG como subsídio para planos de seguro em áreas urbanas: um ensaio em Caraguatatuba $(S P)$, Universidade Estadual Paulista (UNESP), Rio Claro, 196 p.

Balaji, D; Sankar, R; Karthl, S. (2005). GIS approach for disaster management through awareness - an overview. Disponível em: http://www. gisdevelopment.net/application/natural_ hazards/overview/nho0012.htm.

Beck, Ulrick (1986). Sociedade de risco: rumo a uma nova modernidade. Tradução de Sebastião Nascimento. São Paulo: Ed. 34.

Castro, M. Cleber et al. (2005). Riscos Ambientais e Geografia: Conceituações, Abordagens e Escalas. Anuário do Instituto de Geociências - UFRJ, Vol. 28, Rio de Janeiro, p. 11-30.

Cerri, E. da S. Leandro, Amaral, P. Claudio (1998). Risco geológico. In: Oliveira, A. M. dos S., Brito, S. N. A. Geologia de Engenharia. Associação Brasileira de Geologia de Engenharia, São Paulo, p. 301-10.

Christofoletti, Antônio (1990). Modelagem de Sistemas Ambientais. Ed. Edgard Blucher, São Paulo, $256 \mathrm{p}$.

Cutter, Susan (2003). The Vulnerbility of Science and the Science of Vulnerability. Annals of the Association of American Geographers, 93(1), p.1-12.

Dagnino, S. Ricardo; Carpl, Salvador (2007). Risco Ambiental: Conceitos e Aplicações. Climatologia e Estudos da Paisagem, p. 50-55.

Dilley M, Boudreau T.E (2001). Coming to terms with vulnerability: a critique of the food security definition. Food Police. 26(3), p. 229-47.

Egler, Claudio A.G (1996). Risco Ambiental como Critério de Gestão do Território: Uma aplicação à Zona Costeira Brasileira. Revista Territorio. Vol 1(1), Rio de Janeiro, p. 31-41.

Faugères, Lucien (1990). La dimension des faits et la théorie du risque. Le Risque et la Crise, Foundation for International Studies, Malta, p. 31-60.

Faugères, Lucien (1991). La géo-cindynique, géocience du risque. Bulletin de l'Association de Géographes Francais, n.3, Paris, p. 179-193.

Giddens, Antony (1991). As conseqüências da modernidade. tradução de Raul Fiker. - São Paulo: Editora UNESP. 
Guivant, S. Julia (1998). A trajetória das análises de risco: Da periferia ao centro da teoria social. Revista Brasileira de Informações Bibliográficas, ANPOCS, p. 3-38.

Guivant, S. Julia (2001). A teoria da sociedade de risco de Ulrich Beck: entre o diagnóstico e a profência, Revista Brasileira de Informações Bibliográficas, ANPOCS, p. 95-112.

Hewitt, Kenneth (1997). Regions of Risks: A Geographical Introduction to Disasters. LONGMAN, W. Addison, Essex, England, 358 p.

Kalipeni Ezekiel (2001). Health and disease in southern Africa: a comparative and vulnerability perspective. Social Science \& Medicine. Vol. 50, p. 965-983. Disponível em:

http://www.sciencedirect.com/science.

Knight, Frank (1921). Risk, uncertainty and profit. In: the History and Method of Economics. Chicago: Univ. Chicago Press, 1956

Kovach, L. Robert (1989). Earth's fury: a introduction to natural hazard and disasters. p. Nova Jersey: Prentice Hall, 1995.

Lourenço, Luciano (2007). Riscos naturais, antrópicos e mistos. Territorium, Revista da Associação Portuguesa de Riscos, Prevenção e Segurança, Lousã, n¹4, p. 107-111. Disponível em: http:// www.uc.pt/fluc/nicif/riscos/Documentacao/ Territorium/T14_artg/T14NNR01.pdf.

Lourenço, Luciano (2008). «Perigos» das «Cartas de Risco». Comentários ao modelo proposto no Guia Técnico para a elaboração do PMDFCI. Territorium, Revista da Associação Portuguesa de Riscos, Prevenção e Segurança, Lousã, $n^{\circ} 15$, p. 122-126. Disponível em: http://www.uc.pt/ fluc/nicif/riscos/Documentacao/Territorium/ T15_artg/T15NNR11.pdf.

Lourenço, Luciano ((Coord.) 2008). Riscos Naturais, Antrópicos e Mistos. Homenagem ao Professor Doutor Fernando Rebelo. Departamento de Geografia da Faculdade de Letras da Universidade de Coimbra, Coimbra, 902 p.

Marandola, J. Eduardo; Hogan, J. Daniel (2004). Natural Hazard: O Estudo Geográfico dos Riscos e Perigos. Encontro Transdisciplinar sobre Espaço e População. ABEP. Vol. VII nº. 2, 13-15. São Paulo. p.15.

Marandola, J. Eduardo (2004). Uma ontologia geográfica dos riscos: duas escalas, três dimensões. Geografia - Rio Claro, v. 29, n. 3, São Paulo. p. 315-338.
Marandola, J. Eduardo; Hogan, J. Daniel (2005). Vulnerabilidade e Riscos: entre a geografia e a demografia. XIV Encontro Nacional de Estudos Populacionais da Abep. ABEP. São Paulo. p. 29-53.

Marandola, J. Eduardo; Hogan, J. Daniel (2006). As Dimensões da Vulnerabilidade. Em Perspectiva. São Paulo, p. 33-43.

Marandola, J. Eduardo; Hogan, J. Daniel (2009). Vulnerabilidade do lugar vs. vulnerabilidade sócio demográfica: implicações metodológicas de uma velha questão. Revista Brasileira de Estudos de População, São Paulo. Vol. vol.26 no.2. p 161-181.

Marcelino, V. Emerson (2008). Desastres Naturais $e$ Geotecnologias: Conceitos Básicos. Instituto de Pesquisas Espaciais (INPE). São José dos Campos. 39 p.

Nascimento, S. José Antônio (2011). Vulnerabilidade a eventos climáticos extremos na Amazônia Ocidental: uma visão integrada na bacia do Rio Acre. Universidade Federal do Rio de Janeiro, Rio de Janeiro. 285 p.

Pearson, E; Wadge, G; Wiscoskl, A. P (1991). An integrated expert system/GIS approach to modeling and mapping natural hazards. In: European conference on GIS (EGIS'91), Session 26, Belgium,p. 763-771.

Pedro, Isabel (2014). Riscos e perigos em tradução. Considerações sobre terminologia nas ciências cindínicas. In: Lourenço e Tadim (coord.) Realidades e Desafios na Gestão dos Riscos. Diáçogo entre Ciência e Utilizadores, NICIF, Faculdade de Letras da Universidade de Coimbra, p. 55-60

Pelletier, Philippe (2007). Um Japão sem riscos? In: Veyret, Yvette. (org.) Os Riscos: o Homem como agressor e vítima do meio ambiente. São Paulo: Contexto, P. 201-220.

Pessanha, Lavínia Davis Rangel (1998). O Pensamento de Antony Giddens e suas Lacunas - Implicações para a discussão do tema das instituições modernas. Revista Brasileira de Informações Bibliográficas, ANPOCS. p. 13.

Rebelo, Fernando (1999). A teoria do risco analisada numa perspectiva geográfica. Cadernos de Geografia. Coimbra, 18, p. 3-13.

Rebelo, Fernando (2001). Riscos Naturais e Acção Antrópica. Imprensa da Universidade de Coimbra, Coimbra, 274 p. 
Rebelo, Fernando (2014). Terminologia do risco. Origens, dificuldades de tradução e bom senso. In: Lourenço e Tedim (coord.) Realidades $e$ Desafios na Gestão dos Riscos. Diálogo entre Ciência e Utilizadores, NICIF, Faculdade de Letras da Universidade de Coimbra, p. 7-17

Smith, Keith (1992). Environmental Hazards. Assessing Risk and Reducing Disaster, Londres, Routledge, p. 1-99; 209-237; 258-288.

Tobin, G. A; Montz, B. E. (1997). Natural hazards: explanation and integration. The Guilford Press, New York. 388p.

Torres, G. Haroldo da (1998). A Demografia do Risco Ambiental. XI Encontro Nacional de Estudos Populacionais da Abep, 19-22 Outubro, p. 3077-3097.

Tuan, Yi-Fu (1883). Espaço e lugar: a perspectiva da experiência. São Paulo: DIFEL. 250 p.
UN-ISDR. UNITED NATIONS OFFICE FOR DISASTER RISK. REDUCTION (2004). Living with risk: a global review of disaster reduction initiatives. Geneva: Disponível em: http://www.unisdr.org/files/657_lwr1.pdf.

VeyreT, Yvette (2007). Os Riscos: O homem como agressor e vítima do meio ambiente. Contexto, São Paulo, p. 320.

Veyret, Yvette; Meschinet R. Nancy (2007). O risco, os risco. In: Veyret, Yvette (org.) Os Riscos: o homem como agressor e vítima do meio ambiente. São Paulo: Contexto. P. 23-79.

Vieillard-Baron, Hervé (2007). Os risco sociais. In: Veyret, Yvette (2007). (Org). Os Riscos: O homem como agressor e vítima do meio ambiente. São Paulo: Contexto, P. 275-316. 